\title{
Outdoor Play Environment in Early Childhood for Children
}

\author{
$\operatorname{Dr}$ (Mrs.) Florence a. Undiyaundeye \\ Department Of ECCDE \\ Federal College of Education, \\ Obudu, Cross River State \\ Email: atube2001@yahoo.com
}

PHONE: NO. +234 805742 2724/+234 8064127750

\begin{abstract}
Every adult is aware that children enjoy playing. Even before a child is able to grasp an object, bright coloured toys are suspended in a crib or held for him to enjoy. Once the child is able to crawl, stand and walk, the opportunity to explore the environment and play are expanded. Through rich educational programmes young children can demonstrate effective learning and significant development. This even has been developed to explore ways to create an outstanding environment for children under three years. It will examine ways to achieve consistent high standards across education programmes through creating rich, varied and imaginative experiences for children. Outdoor play environment offers the children much needed exercise, sunshine and the opportunity to practice motor skills in a different setting. Through a supportive outdoor play environment, the children are exposed to best support for children's emotional, social, physical development and ways of acquiring communicative and language skills so that they are exceptionally well equipped for school and next steps in their learning. A combination of inspiring and motivated exciting environment provides the child with the grounds for learning through play and experience and a different type of freedom and confidence in exploration of nature and habitat.
\end{abstract}

Keywords: Environment, Outdoor play, Play, Children, Learning and Development

\section{Introduction}

The environment both indoor and outdoor plays an important role in the development of babies and young children from their earliest experiences. Even before birth, the quality of the environment impacts significantly on the foetus development in the womb. in the early days a child's environment is mainly the adults who care for them. The environment gradually widens to include different people and varied surroundings. Children are sensitive to the ambience within any environment. It is important that this is recognized.

A rich and varied environment supports children's learning and development. It gives them confidence to explore and learn in secure and safe, yet challenging, indoor and outdoor spaces. The emotional environment is created by all the people in the setting, but adults have to ensure that it is with children and support their emotions. When children know that their feelings are accepted they learn to express them, confident that adults will help them with how they are feeling. Being outdoors has a positive impact on children's sense of well-being and helps all aspects of children's development. Outdoor opens children the opportunity for doing things in different ways and on different scales than when indoors. Dempsey (2005) observed that children playing outdoor gives them first-hand contact with weather, seasons and the natural world. It also offers them freedom to explore, use their senses and be physically active and exuberant.

Children learn from and adapt to their environment as they build a sense of self from the attitudes and values of the significant people around them. Adults who are affectionate, interested, reliable and responsive help young children to develop a sense of trust and a positive self-image. Most babies and young children are sensitive to the moods of those around them and they instinctively know when adults are for example, relaxed, tense, pre-occupied or keen or provide focused attention. Babies and children look for both verbal and non verbal messages that communicate respect, value and love. Greenman (2007) feels that the most important message and demonstration to ensure that children are always greeted with a warm welcome upon arrival in early setting is; "creating a positive ethos within a safe, welcoming and nurturing environment by ensuring a high level of involvement and overall sense of belonging for children and families, responding appropriately and positively to children's needs and preference also respecting and valuing children's interest".

\section{Planning Outdoor Positive Environment}


A well planned and sensitively thought out door environment helps to foster and promote a positive sense of self and wellbeing in babies and young children. Goldschmied and Jackson (2004) maintain that "creating a satisfactory visual environment is not a one for all jobs but something that needs to happen continuously. Just as at home we are constantly making small adjustments and improvements changing picture from one place to another, moving a lamp or a plant, a nursery will only look limiting and cared for if the same kind of process is going on". Planning and organizing a playing environment effectively is a key and challenging role for care givers and staff team in early childhood centres.

When considering play ground development, it is important to consult with all the stakeholders to discover their views on the outdoor area. The stakeholders include the children, the staff or care givers, parents, school managers/administrators and the wider community.

The process of change occurs in four stages'

Self Evaluation: Where are we now?

Vision planning: Where do we want to be?

Active planning: How can we get there? And

Implementation: Making the changes.

Every outdoor space will be different and will have limitations that need to be marked within the setting and need to be considered in the available space for the children to play and how to make most of them compatible with the resources available. Gabbard (2008). When making changes, ensure that the ongoing plan for maintenance and care is in place particularly for natural or growing spaces. Even though every space is unique, there are some key factors that are applicable to all spaces, they include; access and security, shelter and studies, appropriate chatting, appropriate storage, variety surfaces, the four elements (earth, water, air and fire) natural spaces, growing spaces, active spaces, reflective spaces, creative spaces and social spaces. Note that all of these factors overlap and connect rather than operate in isolation to allow the children the opportunity to explore freely in the outdoors. Risk management processes should be shared with the children where possible, to enable them to make appropriate choices and manage risk themselves according to their developmental ages.

Outdoor learning is most significant and effective when complementary to the indoor space. Ideally both environments are available simultaneously to the children through a seamless transition space and the children should be able to choose between spaces in free flow provision. Play and learning that flow seamlessly between indoors and outdoor enable children to make the most of the resources and materials available to them and develop their ideas without unnecessary interruption. Karas (2007). Playing is vital especially the outdoor which is vial for children's physical health and development, emotional well being and promotes cognitive development and achievement. It enables children's freedom to explore and develop their physical boundaries to take risks and to discover the real world with all the child's self esteem and confidence. Outside is dynamic, liberating, give room for active, noisy, messy and work on a large scale. One couldn't predict what might happen and as such it provides opportunities to experience how to deal with them. Young children's basic need for well being and involvement and their urge to explore and make sense of the world is developed through risk quality play in an outdoor environment.

\section{The Importance of Taking Infants and Toddlers Outdoors}

One of the more challenging criteria to meet on the infant - toddler environment rating scale is taking infant and toddlers outdoors to play. Parents often don't want their infants outdoors because they will get sick or there may be no time to take young children outside. When there are so many routines and individualized schedules. Why is it important to take infants and toddlers outdoor? How do you set up a safe outdoor environment for children? What do you do with them once you get them outdoor? During the first few years of life, infants and toddlers are trying to make sense of their world. One of the ways they do this is by soaking up every noise, every sound and every experience that they have. They then take this information and come up with ideas about how the world works. So not only is being outdoors an enjoyable experience for infants and toddlers, it is critical for cognitive development.

in the first three years of a child's life, brain synapses is formed at a rapid rate. These synapses are formed based on the richness of the child's sensory environment. So, it would make sense that childcare providers would want to provide a stimulating environment for infants and toddlers both indoors and out doors. in addition, the knowledge they gain outdoors provides a foundation to literacy and science learning (Harm, Cryer and Clifford, 2006) 
Outdoor experiential learning also promotes early language development. Having a rich sensory experience gives young children something to talk about. When an infant feels the leaves or the toddler notices the airplane in the sky, they are more inclined to verbalise this experience because it will elicit a favourable response by their care givers. This verbalization to others also promotes social development. Even infants who do not have the ability to physically play with others are able to watch others, which is the first step in social development (Oesterreich, 1995)

Outdoor experiences are critical for infants and toddler's physical development. Gabbard (1998) observed that the "window of opportunity for acquiring basic motor movement is from prenatal to five years of age. During this time, the brain gathers and stores information and a solid foundation for movement activities is built. Infants need interesting things to look at from a horizontal and vertical position. They need materials and space to practice crawling and things to pull up on, so that they can learn to walk. Toddlers also need space and materials that will help them act out preposition over under, on top of, inside, outside, behind, in front of, up and down (Riukin, 2000)

\section{Care Recommendation of the Child in Outdoor Play Environment}

Infants and toddlers require supervision when they are outdoors. Because they explore their world, they often taste it first which can result in more exposure to germs or to choking hazards. Therefore, it is necessary to make sure that all potential choking hazards are removed from them, the area and that care givers are in close proximity to children so that they can remove unwanted objects from their mouths.

They need surface that will allow them to move around easily. This surface should be accessible to all children. It should be made of materials that will not be too hot in the changing weather. It should provide comfort, tactile experiences and protect children that are still mastering balance, there must be enough room to move without hitting a hard surfacing material or sharp edges.

The outdoor material need to be challenging the children but base on realistic expectation about what children at their age can or cannot do. All anchored equipment should be designed based on guidelines for children ages $6-23$ months. Many playground manufacturers are not aware of the new standards, therefore, it is important to check with them before purchasing equipment bearing in mind that these kids are just learning to walk. They do not need high climbers or ladder because they haven't mastered taking large steps. Walking across a low, wide bridge or balance beam is challenging to them. Playing with riding toys, tricks, weapons where they can put other materials in it and different sizes of bells are just as interesting as climbing onto a structure.

Beyond the activities already mentioned there are many interesting and fun experiences that you can provide for both infants and toddlers outdoor.

\section{For children 0 - 3 months}

Provide a bucket for the baby to lay on point out the leaves moving, let them feel the leave and grass and point out nature sound that they hear

\section{For Children 3-6 months}

With the blanket let the child explore on his or her stomach. Bring out objects to grasp, blocks, or activity gyms. Again plant out the things happening in nature and let them feel natural objects.

\section{For 6 - 9 months}

Create a texture part on the ground using assorted textures such as carpets, squares, rings, grass and resilient surfaces. The children can crawl along this path to explore large motor skills and sensory stimulations, provide tunnels, bells and safe sensory tubes.

\section{For $9-12$ months}

Provide balls, bubbles and toys that are small enough for them to practice standing. for early walker provide simple push toys. Attach musical toys, activity centers and mirrors to fence at different levels for kids who are still crawling and for those who are standing.

\section{For toddlers}

Continue to add more materials that reflect the variety of developmental skills. Ring some music outdoors so that they can practice dancing, jumping. 
Provide a garden outdoors so that the children can learn about soil, plants and insects.

Remember that the experiences that these infant and toddlers have outdoors while they are in child care, may infact be the only opportunity they may have to really explore the outdoors.

\section{Conclusion}

By taking children outdoor a wonderful opportunity of getting up a good model for parents to follow is provided. If children learn to love being outdoors when they are young it will make them healthier. It will also help ensure that they will take better care of our world when they become adults. The outdoor environment is where children come into contact with the ever changing system of nature and the four elements. It is the dynamic world of living and non living things that aimlessly interact through time and space. The seasonal changes and differing weather conditions provide children with a sense of time and place and later endless investigation possibilities. Every child has a target to daily outdoor learning and as much value should be placed on the outdoor environment as inside. The same amount of resources, planning, time and money should go into providing the outdoor space as the indoor one. It is not an optional extra. The outdoor excitement can provide more freedom for a greater range of play and learning and it is every child's entitlement.

\section{References}

[1] Dempsey, J. (2003). Outdoor Play and Play ground for Infants and Toddlers (Electronic Version) Available online accessed October 18, 2007

[2] Gabbard, C. (1998). Windows of opportunity for Early Brain and Motor Development. Journal of Physical Education, Recreation and Dance Vol., 69 pp 54 - 56

[3] Gabbard, L.E (2008). Toddlers in Physical Play (Elective version). Journal of the National Association for the Education of Young Children. Retrieved (October 18, 2009) from 222.jounral.meye.org

[4] Goldschmied, E. and Jackson, J. (2004). Outdoor play environment. A Handbook on Early Child Care Education. Michigan State University Dubai- UAE

[5] Greenmen, J. (2007). Caring spaces, loving places, children's environment that work. Red mind W.A Exchange Press

[6] Harm, Cryer \& Clifford, R. (2006). Infant-Toddler Environment Rating Scale - Revised Edition. New York NY: Teachers College Press.

[7] Karas, B. (2007). Family Child Care Handbook Pin 15411 pp 192 - 196. Ames IA: LOWA State University extension

[8] Oesterreich, L. (2009). Ages and Stages - New born to 1 year (electronic version) in L Oesterreich B. Holt

[9] Riukin, M.S (2000). Outdoor Experiences for Young Children (electronic version) ERIC Digest,. Retrieved October 11, 2007 from www.eric.digest.org/20001-3/children.htm(ERIC) 